\title{
A combined numerical and experimental approach for determining the contact temperature in an industrial ironing operation
}

Üstünyagiz, Esmeray; Nielsen, Chris V.; Christiansen, Peter; Martins, Paulo A.F.; Altan, Taylan; Bay, Niels Oluf

Published in:

Journal of Materials Processing Technology

Link to article, DOI:

10.1016/j.jmatprotec.2018.09.015

Publication date:

2018

Document Version

Peer reviewed version

Link back to DTU Orbit

Citation $(A P A)$ :

Üstünyagiz, E., Nielsen, C. V., Christiansen, P., Martins, P. A. F., Altan, T., \& Bay, N. O. (2018). A combined numerical and experimental approach for determining the contact temperature in an industrial ironing operation. Journal of Materials Processing Technology, 264, 249-258. https://doi.org/10.1016/j.jmatprotec.2018.09.015

\section{General rights}

Copyright and moral rights for the publications made accessible in the public portal are retained by the authors and/or other copyright owners and it is a condition of accessing publications that users recognise and abide by the legal requirements associated with these rights.

- Users may download and print one copy of any publication from the public portal for the purpose of private study or research.

- You may not further distribute the material or use it for any profit-making activity or commercial gain

- You may freely distribute the URL identifying the publication in the public portal 


\section{Accepted Manuscript}

Title: A combined numerical and experimental approach for determining the contact temperature in an industrial ironing operation

Authors: Esmeray Üstünyagiz, Chris V. Nielsen, Peter Christiansen, Paulo A.F. Martins, Taylan Altan, Niels Bay

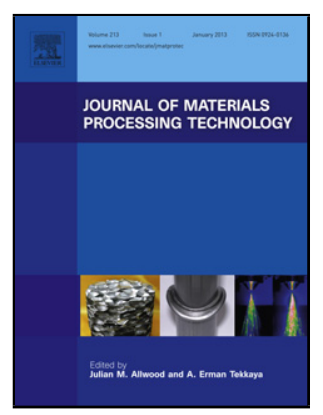

PII:

DOI:

Reference:

S0924-0136(18)30412-6

To appear in: Journal of Materials Processing Technology

Received date: $\quad 6-4-2018$

Revised date: $\quad 17-8-2018$

Accepted date: $\quad 11-9-2018$

Please cite this article as: Üstünyagiz E, Nielsen CV, Christiansen P, Martins PAF, Altan T, Bay N, A combined numerical and experimental approach for determining the contact temperature in an industrial ironing operation, Journal of Materials Processing Tech. (2018), https://doi.org/10.1016/j.jmatprotec.2018.09.015

This is a PDF file of an unedited manuscript that has been accepted for publication. As a service to our customers we are providing this early version of the manuscript. The manuscript will undergo copyediting, typesetting, and review of the resulting proof before it is published in its final form. Please note that during the production process errors may be discovered which could affect the content, and all legal disclaimers that apply to the journal pertain. 


\title{
A combined numerical and experimental approach for determining
} the contact temperature in an industrial ironing operation

Esmeray Üstünyagiz ${ }^{\mathrm{a}, *}$, Chris V. Nielsen ${ }^{\mathrm{a}}$, Peter Christiansen ${ }^{\mathrm{a}}$, Paulo A.F. Martins ${ }^{\mathrm{b}}$, Taylan Altan ${ }^{\mathrm{c}}$ and Niels Bay ${ }^{\mathrm{a}}$

${ }^{a}$ Department of Mechanical Engineering, Technical University of Denmark, 2800 Kgs. Lyngby, Denmark

${ }^{b}$ Instituto Superior Tecnico, Universidade de Lisboa, 1049-001 Lisbon, Portugal

${ }^{c}$ Center for Precision Forming (CPF), The Ohio State University, Columbus, OH 43210, U.S.

Corresponding author. Tel.: +45254728; fax: +45251960

E-mail address: esustu@mek.dtu.dk

\begin{abstract}
Tribological conditions in forming operations depend on several parameters such as tool-workpiece interface pressure, surface expansion, sliding length, sliding speed, tool and workpiece materials and the roughness of the parts. Among indirect parameters, the most influential one is the tool-workpiece interface temperature, which directly influences the lubricant performance. Prior to testing new tribo-systems to determine their limits of lubrication, it is therefore important to find the interface temperature. However, measurement of the interface temperature in metal forming is difficult. The present work investigates the determination of the interface temperature in an industrial ironing operation, where severe process parameters lead to lubricant film breakdown and galling after several strokes. The methodology combines finite element simulations and experimental measurements. The overall procedure is based on a steady-state thermal analysis to determine the temperature distribution within the tool and a transient thermo-
\end{abstract}


mechanical analysis of the ironing process when steady-state conditions are achieved. Results show that the proposed methodology applied to a single stroke can effectively and accurately predict the interface temperature in the test tool, thus avoiding the otherwise required thermo-mechanical FEM analyses of hundreds of strokes to reach steady-state. Furthermore, the influence of parameters, such as the predicted steady-state tool temperature, the friction coefficient and the heat transfer coefficient on the contact temperature, is analysed. It is concluded that the frictional heating is the primary cause for the peak temperature. By calibration of the friction coefficient and the heat transfer coefficient to ensure matching of the numerical results and the experimental measurements, a maximum tool-workpiece interface temperature of $158^{\circ} \mathrm{C}$ was determined during the forward stroke and $150^{\circ} \mathrm{C}$ during the backward stroke.

\section{Keywords}

Metal forming; Tool-workpiece interface temperature; Numerical simulation; Thermo-mechanical model; Tribology

\section{Introduction}

Up to $95 \%$ of the mechanical energy involved in metal forming processes is transformed into heat. The generated heat partly stays in the deformed material, partly flows into the undeformed region, the tooling and the environment. The distribution and the level of the temperature in a forming process mainly depend on the initial temperature of each component, the heat generation through friction and plastic deformation, and the heat transfer between the parts and the lubricant and the parts and the environment (Farren and Taylor, 1925).

The prediction of the tool-workpiece interface temperature in a metal forming process is an important issue due to its effect on friction and lubrication. Increasing temperature implies lower viscosity of the lubricant, diminishing film thickness and the risk of film breakdown, metal-to-metal contact between tool and workpiece surface, pick-up and galling (van der Heide and Schipper, 2003, Olsson et al., 2004, Friis et al. 2008, Ceron et al., 2014). Increased temperature due to forming may on the other hand also facilitate the process in some cases. In solid film lubrication (e.g. in cold forging lubrication with conversion coating and soap), increasing temperature results in lower friction 
(Wibom et al., 1994, Bay et al., 2011). In boundary lubrication, the lubricant additives may be activated at a certain temperature level. By chemical or physical adsorption or by chemical reaction, a boundary layer of only one or a few molecules can prevent metal-metal contact to be formed (Schey, 1970).

Determination of the tool-workpiece interface temperature has been a subject of intense research. A way to measure the interface temperature experimentally is to establish a hot junction between the thermocouple wires at the contact interface (Jimbo et al., 1998). Alternatively, the two conductor metals can be placed onto a surface if it has uniform temperature and is conductive (Henningsen et al., 1998). When the access to the contact is limited, the thermocouple wires can be welded into the tool, close to the surface contacting the workpiece material, while making sure that the drilled holes do not weaken the rigidity of the tool (Nielsen, 2011). This indirect measurement technique requires extrapolation by analytical or numerical solutions for an accurate estimation of tool-workpiece temperature.

Pereira and Rolfe (2014) have studied sheet stamping of high strength steel on a single-action, mechanical press in order to investigate the friction- and deformation-induced heating. They developed a thermo-mechanical, numerical model and validated their predictions against temperature measurements at a low speed. Then, the numerical model was used to replicate the production-type operation condition with 32 strokes per minute (spm). They found that the frictional heating was the primary cause for the peak temperature at the die surface. However, the developed model did only emulate single-stroke operations. Fallahiarezoodar et al. (2016) have investigated the temperature increase in the tool-workpiece interface in U-channel drawing and deep drawing for single as well as multiple strokes. They found that the maximum temperature rise in the tool-workpiece interface reached $120{ }^{\circ} \mathrm{C}$ in only nine strokes. It is vital to ensure that the process is in a steady-state condition before determining the interface temperature. Nielsen et al. (2011) predicted the tool-workpiece temperature for an industrial deep drawing and ironing operation of AISI 304 stainless steel, performed in a five-step progressive tool. They measured the tool temperature $2 \mathrm{~mm}$ from the contact surface in the final ironing operation during which the wall thickness was reduced by $25 \%$. The developed thermomechanical model simulated 100 strokes. The numerically calculated temperature was then compared with the experimental measurements for validation of the model. They determined the maximum interface temperature to $110^{\circ} \mathrm{C}$ in the production test at $100 \mathrm{spm}$ using a PM tool steel, Vancron 40, as tool material and a chlorinated paraffin oil, Castrol PN226, as lubricant. Afterwards, they tested various tribo-systems in laboratory conditions using the 
previously found industrial interface temperature. However, they reported very long CPU time and convergence problems using DEFORM ${ }^{\mathrm{TM}}$ 2D. State of the art shows that determination of interface temperatures in industrial metal forming is performed either for a limited number of strokes without ensuring steady-state production conditions or by inefficient numerical modelling.

The present study reports on the determination of the contact temperature in a tribologically severe multistage deep drawing and ironing process applied by the Danish company Grundfos. The aim is to analyse the tool-workpiece interface temperature in production in order to carry out subsequent laboratory tests of several alternative tribosystems under realistic conditions. The analysis is based on a recently developed combined numerical-experimental approach (Ceron et al., 2014). The experimental measurements of temperature in a few points of the tool are the inputs to the thermal modelling of steady-state conditions. The determined temperature distribution in the tool is used as a boundary condition in the subsequent thermo-mechanical analysis. In this way, the thermo-mechanical model simulates the stage when the production is already in a steady-state condition, thereby avoiding the simulation of the preceeding hundreds of strokes, which leads to steady-state conditions. The model is validated by experimental measurements, and it is furthermore tested with and without inclusion of frictional heating to evaluate the reliability of the thermo-mechanical coupling. Finally, the sensitivity of the model is examined to estimate the effect of the initial steady-state temperature distribution of the tool, varying friction coefficient and heat transfer coefficient.

\section{Experimental Set-Up}

\subsection{Process Conditions}

The industrial ironing operation is performed on a Raster 400 ton mechanical press with link drive operating at 38 spm. Fig. 1a and $\mathbf{b}$ shows an outline of the ironing operation. 
a)

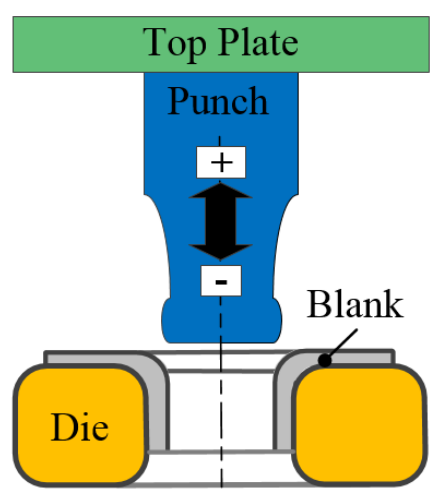

b)

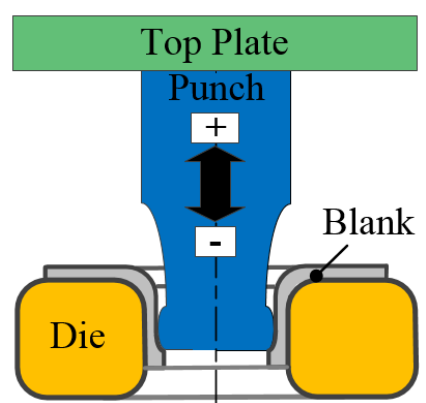

c)

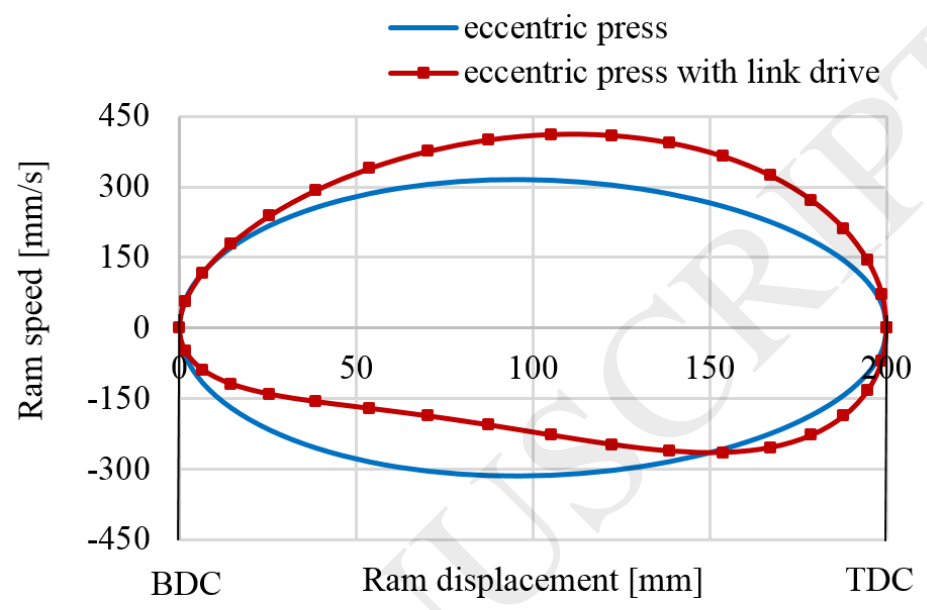

Fig. 1. a) Tool set-up for ironing, open tool, b) set-up during ironing, c) ram speed as a function of ram displacement. The direction of the velocity pattern is clockwise. BDC and TDC indicate the bottom and top dead centers.

The ram speed of the eccentric press can be adjusted by introducing a linkage system. Fig. 1c shows the speed with and without the link drive. Negative ram speed corresponds to the punch moving downwards. Introducing the link drive has the advantage of decreasing the forward forming speed to protect the tool and increasing the backward ejection speed of the punch to increase the productivity.

\subsection{Temperature Measurement}

Fig. 2 shows a schematic of the ironing punch applied. The tribologically critical region is the punch nose encircled by an ellipse in Fig. 2a, where the workpiece-punch contact occurs. 
a)

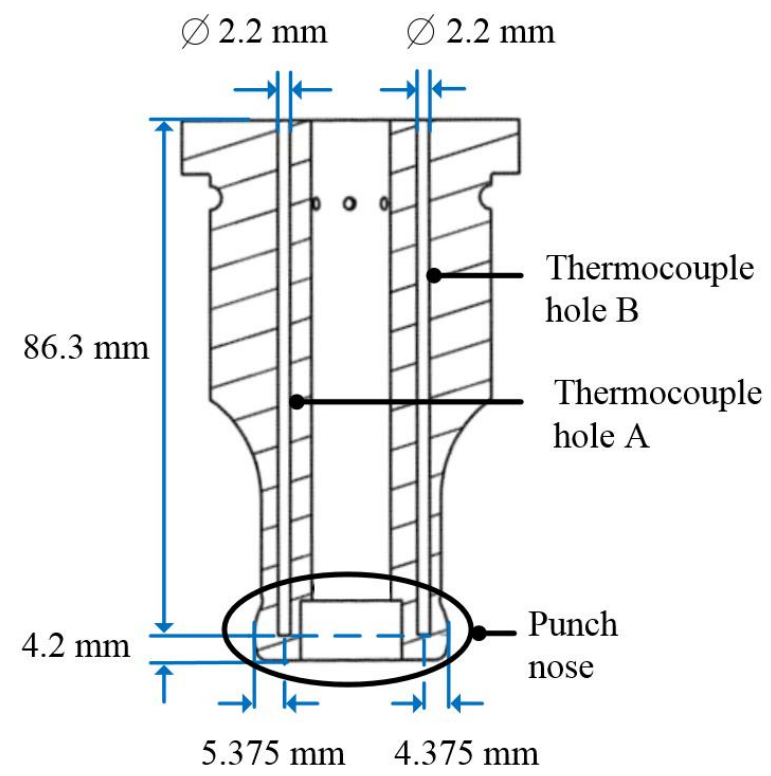

b)
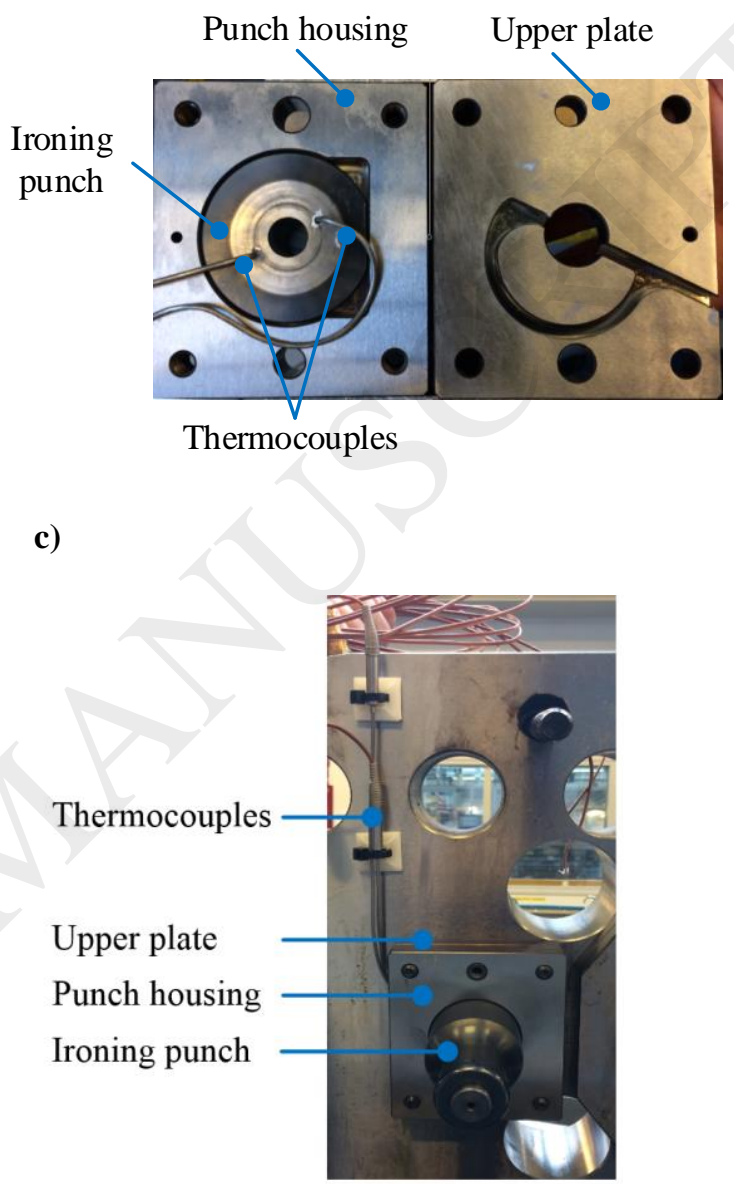

Fig. 2. a) Schematic drawing of the ironing punch, b) top view of the ironing punch with the main components used in the assembly, c) assembled ironing punch and main components seen from below.

The aim is to measure the temperature as closely to the contact interface as possible. Fig. 2a shows the location of the holes for thermocouples. They are $86.3 \mathrm{~mm}$ deep and the diameter is $2.2 \mathrm{~mm}$. The distance from the center of the holes to the outer surface of the punch nose is $4.375 \mathrm{~mm}$ and $5.375 \mathrm{~mm}$, respectively. The holes were manufactured by Electrical Discharge Machining (EDM). For identification of the actual geometry, flatness and positioning of the holes, Computed Tomography (CT) scanning was applied. For the experiments, a T-type thermocouple with a grounded probe was selected. 
Fig. 2b shows the punch from above after mounting of the thermocouples. The punch foot was provided with a plane side matching a plane side of the on the right hand side of the punch-housing in order to prevent the punch from rotating during production. The punch base was supported by an upper plate provided with grooves for the thermocouple wires. Fig. $\mathbf{2 c}$ shows the assembly of the parts. Temperature acquisition was conducted using a National Instruments NI-9212 input module with 8 channels, a maximum sampling rate of 95 measurements per second (per channel) and an accuracy of $0.71{ }^{\circ} \mathrm{C}$.

\section{Numerical Model}

The numerical analysis includes two steps:

a- Steady-state thermal analysis of the punch.

b- Transient thermo-mechanical analysis of the ironing process.

\subsection{Steady-state analysis}

The first step of the numerical analysis is to estimate the temperature distribution in the ironing punch when the steady-state condition is reached. The aim of this model is to determine a temperature field for the punch without simulating the multiple steps before steady-state is obtained.

Fig. 3 shows the 2D-axisymmetric finite element mesh of the punch. The punch was discretized by approximately 1650 quadrilateral solid elements and 2400 nodal points. The nodes subjected to a fixed input temperature value are highlighted in yellow in Fig. 3a. During the actual production, the punch was mounted in the tooling system which restricted direct access to the punch. The yellow nodal points at the punch base were assumed to have a constant temperature $\mathrm{T}_{\text {base }}=40^{\circ} \mathrm{C}$ at steady-state. This assumption was chosen between a lower limit of $28.2^{\circ} \mathrm{C}$ representing the room temperature and an upper limit of $50^{\circ} \mathrm{C}$ representing the punch nose temperature measured by a laser gun two seconds after production stop. The accuracy of the assumption will be analysed in section 4.3.1. Two thermocouples were inserted into the tool with varying distances to the punch nose. The position of the nodes where the temperature was measured are shown in Fig. 3a. Due to limitations in the allocated time for testing in production, 
the output of thermocouple A could not be read. The temperature of thermocouple $\mathrm{B}$ was measured as $\mathrm{T}_{\mathrm{B}}=112^{\circ} \mathrm{C}$ at steady-state. The input temperature of node B in the steady-state model is therefore assigned to $112^{\circ} \mathrm{C}$.

The steady-state thermal analysis was run for thermal isotropic punch material using the implicit solver of the finite element software LS-DYNA. The resulting temperature field is shown in Fig. 3b. The heat capacity and the thermal conductivity of the tool material Vanadis 4E are shown in Table 1. The temperature of each node was saved in an output file, which was subsequently used as input temperature distribution of the punch for the transient thermomechanical coupled analysis.

a)

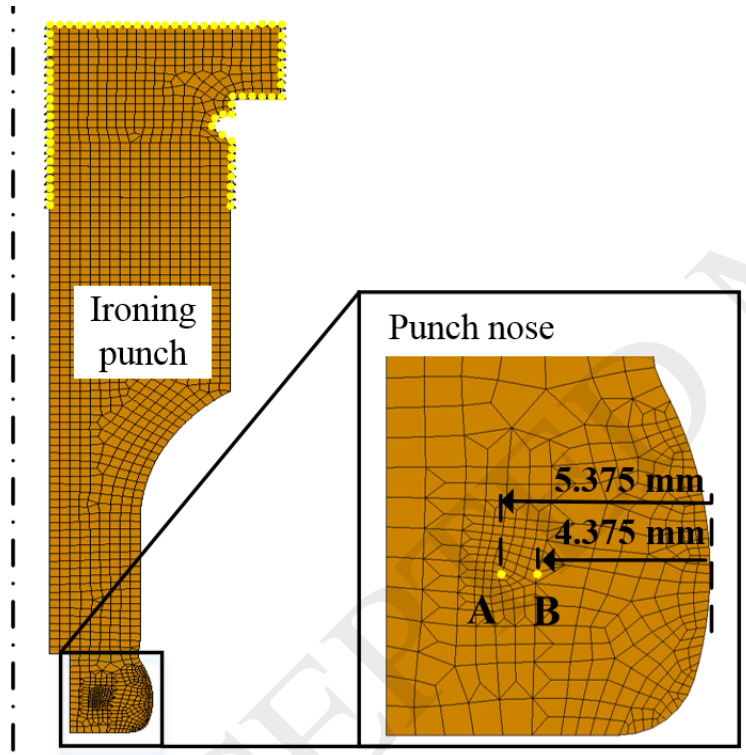

b)

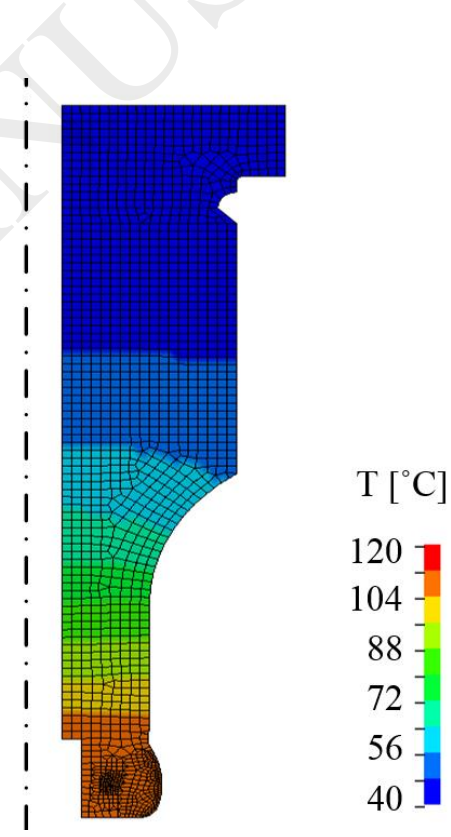

Fig. 3. a) 2D-axisymmetric finite element model of the ironing punch and location of the prescribed temperature boundary input nodes A and B. b) Steady-state temperature distribution in the punch.

\subsection{Transient thermo-mechanical analysis}

The second step of the numerical analysis is based on a thermo-mechanically coupled approach of the ironing process calculating the heat generation due to plastic deformation and frictional work and the heat transfer and heat loss. The frictional work transformed into heat is assumed as $100 \%$ whereas the plastic work transformed into heat is 
assumed as $95 \%$ because the remainder 5\% are assumed to be expended to cause changes in dislocation density, grain boundaries and phases. This procedure allows taking the temperature dependency of the mechanical properties of the workpiece and the tool into account.

In this coupled thermo-mechanical simulation, the calculations are based on the relation given in Fig. 4 .

Mechanical

- Plastic work

- Part contact gap thickness

- Temperature dependent material properties

- Thermal expansion

- Update geometry
Thermal

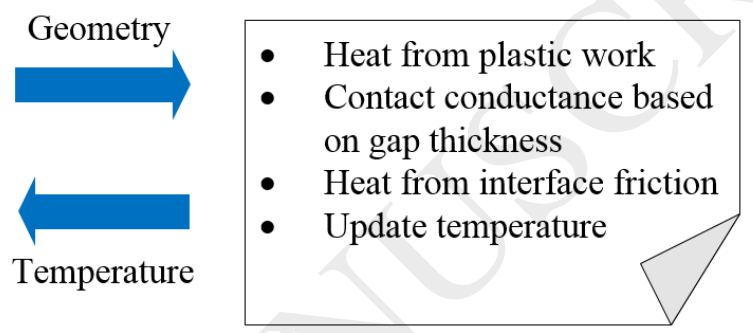

Fig. 4. Representation of thermo-mechanical coupling (Shapiro, 2003).

Fig. 5 illustrates the geometry of the problem and the corresponding finite element model. The model is axisymmetric and neglects the volume of the thermocouple holes, since it corresponds to less than $3 \%$ of the entire volume of the ironing punch and since a previous investigation (Üstünyagiz, 2018) corroborates this assumption showing no significant difference in the distribution of temperature obtained with a full three-dimensional model with thermocouple holes and a simplified three-dimensional model without holes. The overall tooling system was discretized by approximately 5000 quadrilateral solid elements. Initially, the undeformed blank was discretized by 1250 elements and the previous deep drawing operations were simulated. The deformed shape of the part together with the distribution of the variables related to the deformation history was used as input for the thermo-mechanical ironing process.

The tools were assumed rigid. The workpiece material, stainless steel EN 1.4301, was modelled as a piecewise linear plastic material. The stress-strain curve, obtained through plane strain compression tests is illustrated in Fig. 6. No inertia effects were taken into consideration because the workpiece material is strain rate independent at the process working conditions (Doege et al., 1986). 


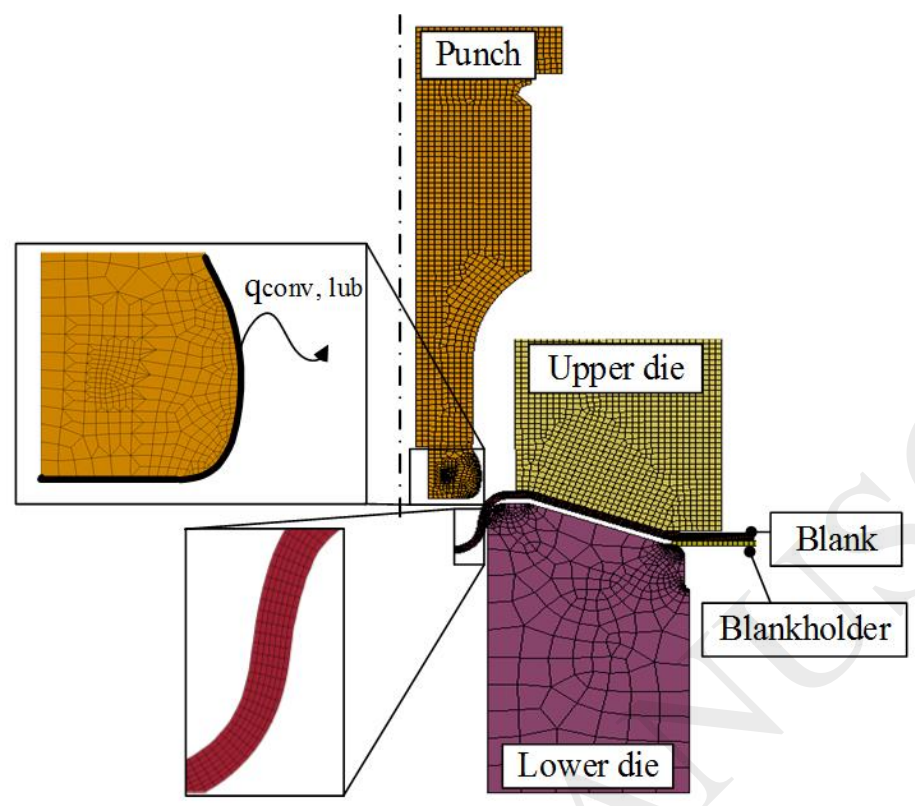

Fig. 5. Representation of 2D-axisymmetric, thermo-mechanical finite element model.

The overall system was assumed to be thermal-isotropic. The material properties used in the numerical model in addition to Fig. 6 are presented in Table 1.

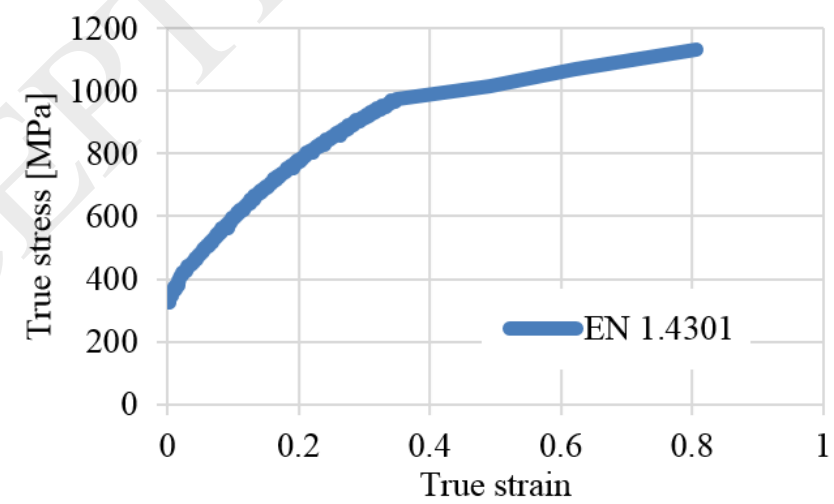

Fig. 6. Flow stress curve for EN 1.4301 obtained from plain strain compression tests. 
Table 1. Material parameters used in numerical simulations.

\begin{tabular}{llll}
\hline Parameter & & $\begin{array}{l}\text { Tool, Vanadis 4E } \\
\text { (Uddeholm, 2017) }\end{array}$ & $\begin{array}{l}\text { Workpiece, 1.4301 (AISI 304) } \\
\text { (Outokumpu, 2013) }\end{array}$ \\
\hline Young's modulus & {$[\mathrm{GPa}]$} & 206 & 200 \\
Poisson's ratio & & 0.3 & 0.3 \\
Structural density & {$\left[\mathrm{g} / \mathrm{m}^{3}\right]$} & 7.7 & 7.9 \\
Heat conductivity & {$[\mathrm{W} / \mathrm{m} \cdot \mathrm{K}]$} & 30 & 15 \\
Heat capacity & {$[\mathrm{J} / \mathrm{kg} \cdot \mathrm{K}]$} & 460 & 500 \\
\hline
\end{tabular}

Measurements with an infrared digital temperature gun with laser point showed an initial temperature of the workpiece strip before ironing of $40^{\circ} \mathrm{C}$. The accuracy of measurement was $+/-1^{\circ} \mathrm{C}$. The lower die temperature was measured similarly to be $42^{\circ} \mathrm{C}$. These values were used as input for the numerical simulations. The initial temperature distribution in the punch was taken from the steady-state analysis. The elements along the punch nose were subjected to heat transfer by flushing of the punch nose with a $30^{\circ} \mathrm{C}$ lubricant. The constant heat transfer coefficient between lubricant and punch was assumed to be $0.15 \mathrm{~kW} / \mathrm{m}^{2} \cdot \mathrm{K}$ (Üstünyagiz, 2018). The constant heat transfer coefficients between the punch and the workpiece strip and between die and the workpiece strip were $100 \mathrm{~kW} / \mathrm{m}^{2} \mathrm{~K}(\mathrm{Olsson}$ et al., 2004). In production, lubrication in the ironing operation is flushed over the punch before as well as after the forward stroke. Friction was modelled by means of the Coulomb friction law and a friction coefficient $\mu=0.04$ was selected (Altan and Tekkaya, 2012), which also matches with experimental temperature measurement as seen later. The maximum shear stress applied in the Coulomb friction law was taken from the material flow stress.

The ram speed used for the numerical analysis is illustrated in Fig. 7. The distance from the punch nose to the flange surface in the bottom dead center was given by the company. The displacement curve in the forward and backward strokes and the corresponding velocity curve are shown in Fig. 7. The corresponding process window, where the ironing process takes place, is identified with a blue rectangular box. This determines the velocity input in the numerical analysis. 


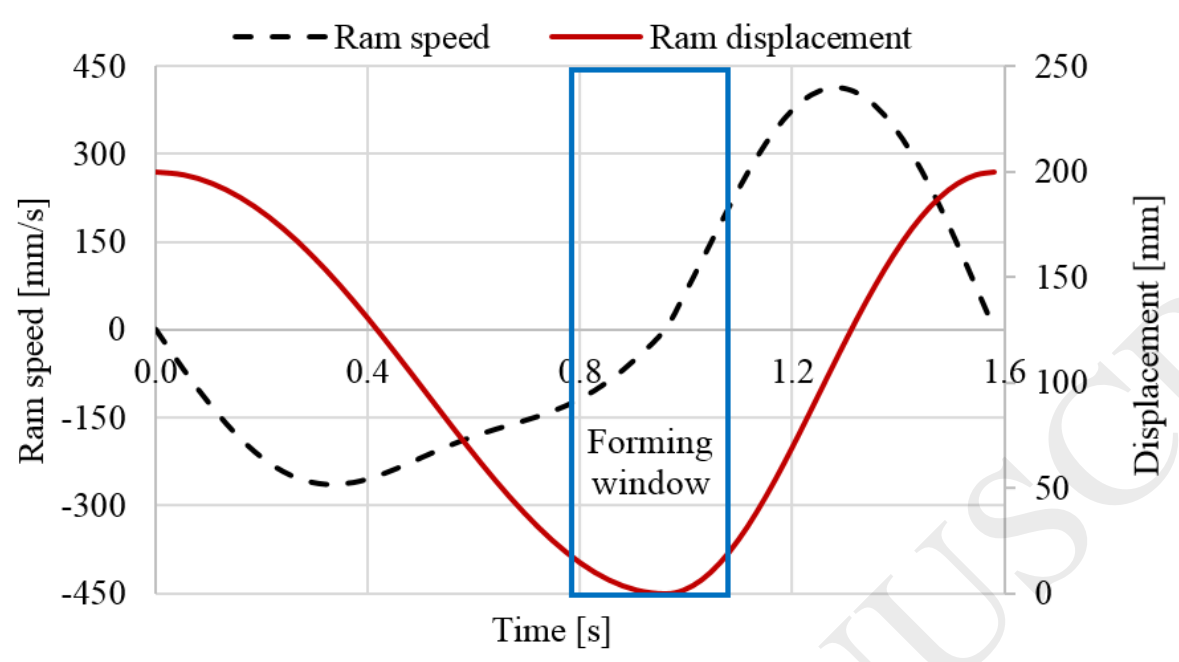

Fig. 7. Ram speed and displacement as a function of time with identification of the ironing process window.

\section{Results and Discussion}

\subsection{Validation of Numerical Results by Experimental Measurements}

Fig. 8a shows the experimental temperature development $T_{B}$ in position $B . T_{B}$ increases rapidly in the beginning of the production and reaches $110^{\circ} \mathrm{C}$ after 100 strokes (i.e., within three minutes). Afterwards, the temperature increases very slowly to $112^{\circ} \mathrm{C}$ at 150 strokes and reaches the maximum value of $114^{\circ} \mathrm{C}$ after 300 strokes. The stroke number 150 is assumed as the begining of the steady-state regime.

The experimental measurement of three consecutive temperature cycles after stroke number 150 is shown in Fig. 8b together with the corresponding numerical simulation. In order to take into account the elastic expansion and deflection of the lower die, its radial displacement was calculated by the numerical model assuming elastic tools. The lower punch expanded $0.03 \mathrm{~mm}$ radially during the forward stroke and $0.015 \mathrm{~mm}$ during the backward stroke. These elastic tool displacements were implemented in the model with rigid tools and the temperature $\mathrm{T}_{\mathrm{B}}$ was calculated, since this turned out to give more stable temperature calculation than running with the elastic tools. The output of the calculated temperature distribution in the punch was used as input for the following stroke. The calculated temperature 
$\mathrm{T}_{\mathrm{B}}$ in three consecutive strokes is shown in Fig. 8b. The difference in the maximum standard deviation between experimental and numerical temperature is $0.04 \%$. Including elastic contraction of the lower die during the backward stroke predicts the temperature evaluation accurately and will be used in the parametric study in the following.

a)

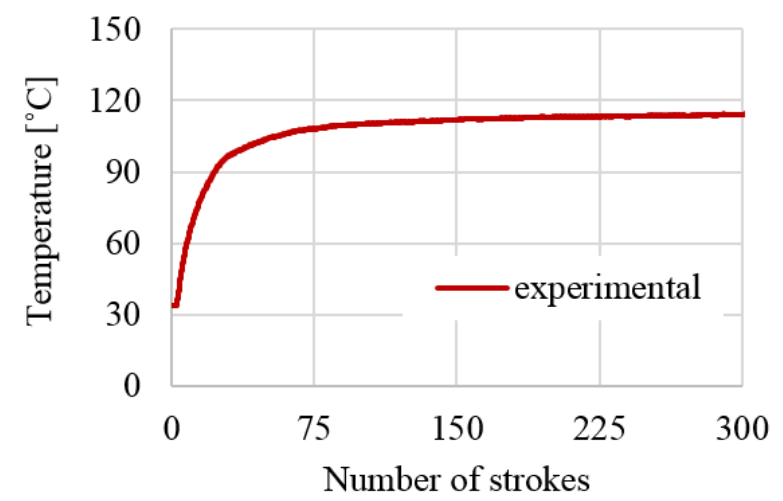

b)

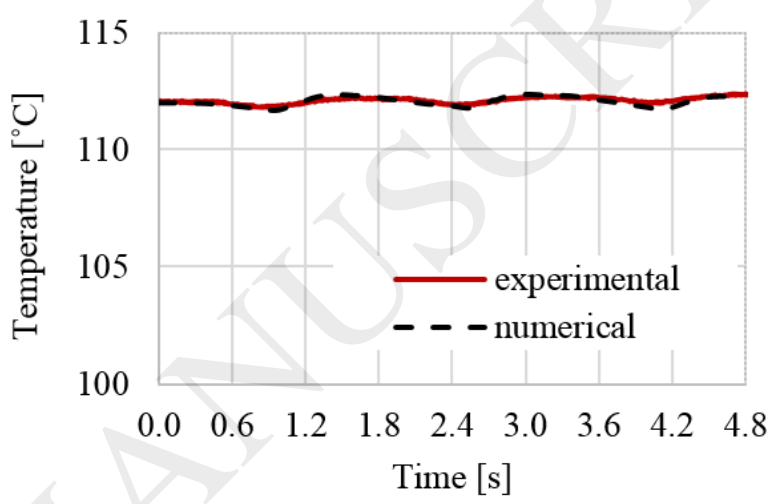

Fig. 8. a) Experimental temperature evolution of thermocouple B in production test and b) numerical and experimental temperature evolution of thermocouple B for three consecutive temperature cycles after stroke number 150 .

\subsection{Numerical Model Analysis}

To analyse the validity of the numerical model, heat generation due to plastic deformation and friction and its effect on the temperature distribution within the workpiece as well as in the punch are studied. For this purpose, the simulations are performed with two friction coefficients, $\mu=0$ and 0.04 . The frictionless condition is chosen to determine the heat generation due to plastic deformation only. The friction coefficient $\mu=0.04$ is the value proposed for this specific ironing application. Justification for this value is given in section 4.3.2. 
a)

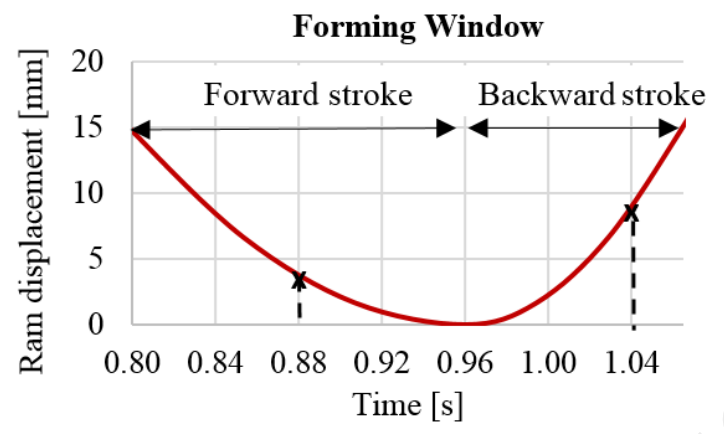

b)
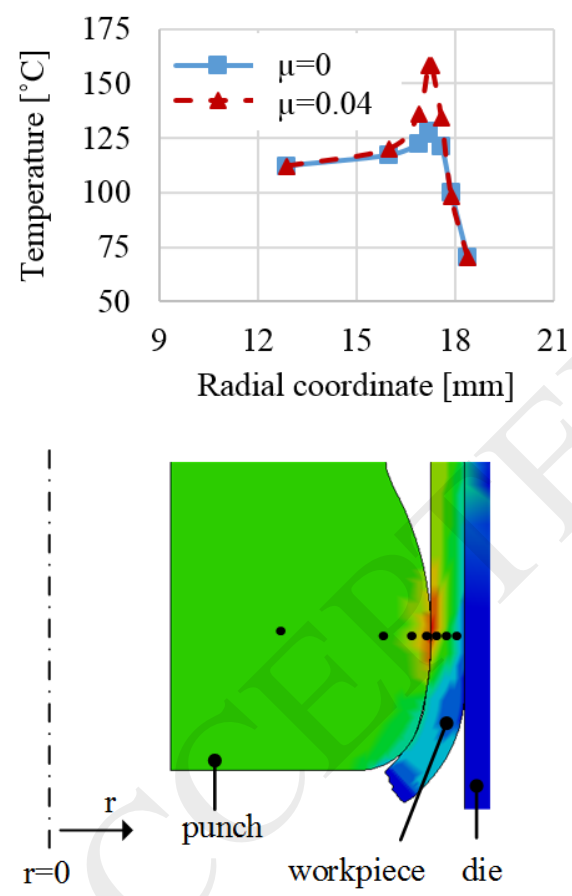

c)
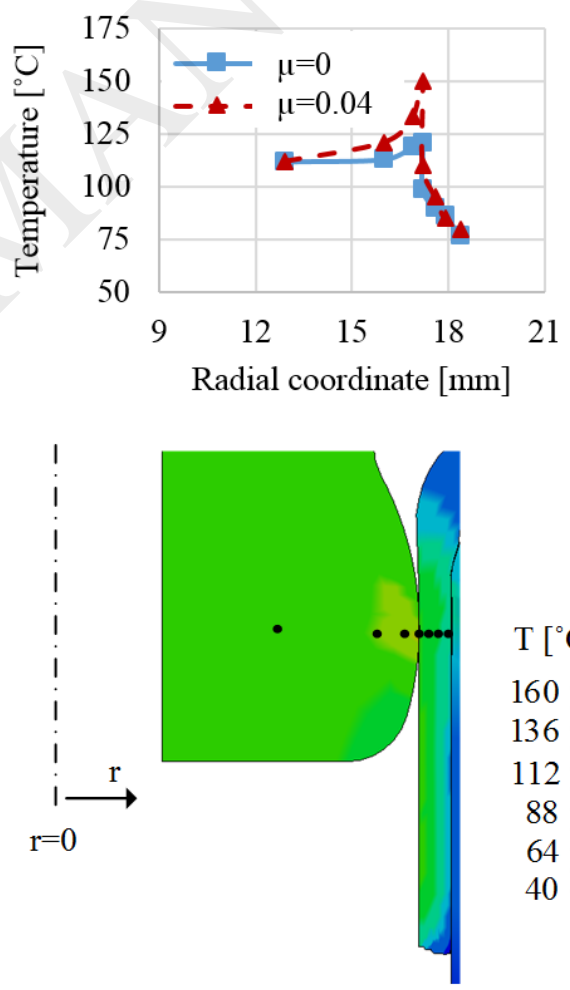

$\mathrm{T}\left[{ }^{\circ} \mathrm{C}\right]$

160

136

112

88

64

40

Fig. 9. a) Ram displacement versus time during the ironing process with the details of forward and backward stroke time intervals and indication of time where the temperature distributions are shown. Temperature distribution with respect to $\mathrm{r}$-coordinate for $\mathrm{b}$ ) forward stroke at $\mathrm{t}=0.88 \mathrm{~s}$, and c) backward stroke at $\mathrm{t}=1.04 \mathrm{~s}$. 
Fig. 9a shows the forming window (refer to Fig. 7) in terms of the ram displacement and time when the ironing process takes place. The cross signs represent the times when the temperature values were taken from the specific nodes along the radial axis. The temperature values were read when the maximum temperature appeared during the forward stroke at $t=0.88 \mathrm{~s}$ and during the backward stroke at $t=1.04 \mathrm{~s}$. Along the radial axis with the same $\mathrm{z}$ coordinate, four nodes in the punch and four nodes in the strip were taken. The selected nodes are shown with black points under each figure in Fig. 9b and Fig. 9c. The illustrated temperature distributions are shown for $\mu=0.04$.

Fig. 9b and Fig. 9c show that frictional heating, when $\mu=0.04$, results in considerably larger temperature gradients along the cross section of tool and workpiece than when $\mu=0$ with a steep rise towards the tool-workpiece contact. As the process continues, during the backward stroke the temperature along the workpiece cross-section becomes more even depending on the contact conditions and heat capacity of the material.

Fig. 10 shows the instantaneous maximum temperature along the punch contact surface as a function of time. For this specific ironing process, the average reduction during the forward stroke is $20 \%$ and $4 \%$ during the backward stroke. The contribution from deformation heating during the forward stroke should therefore be expected to be considerably higher than during the backward stroke. However, it was realised that the collar drawing results in thinner wall at the lower edge of the workpiece, whereas the wall was thicker towards the die corner (See Fig. 9c). As a result, higher strains, and consequently higher temperature, were observed right before the ejection of the punch when $\mathrm{t}=1.03$ $\mathrm{s}$. The results show that the deformation-induced heating gives rise to a temperature of up to $130^{\circ} \mathrm{C}$ during the forward stroke, while the maximum temperature during the backward stroke reaches $120^{\circ} \mathrm{C}$. The instantaneous maximum temperature curve taking both deformation and frictional heating into account increases to a peak temperature of $158^{\circ} \mathrm{C}$ during the forward stroke and $150^{\circ} \mathrm{C}$ during the backward stroke. 


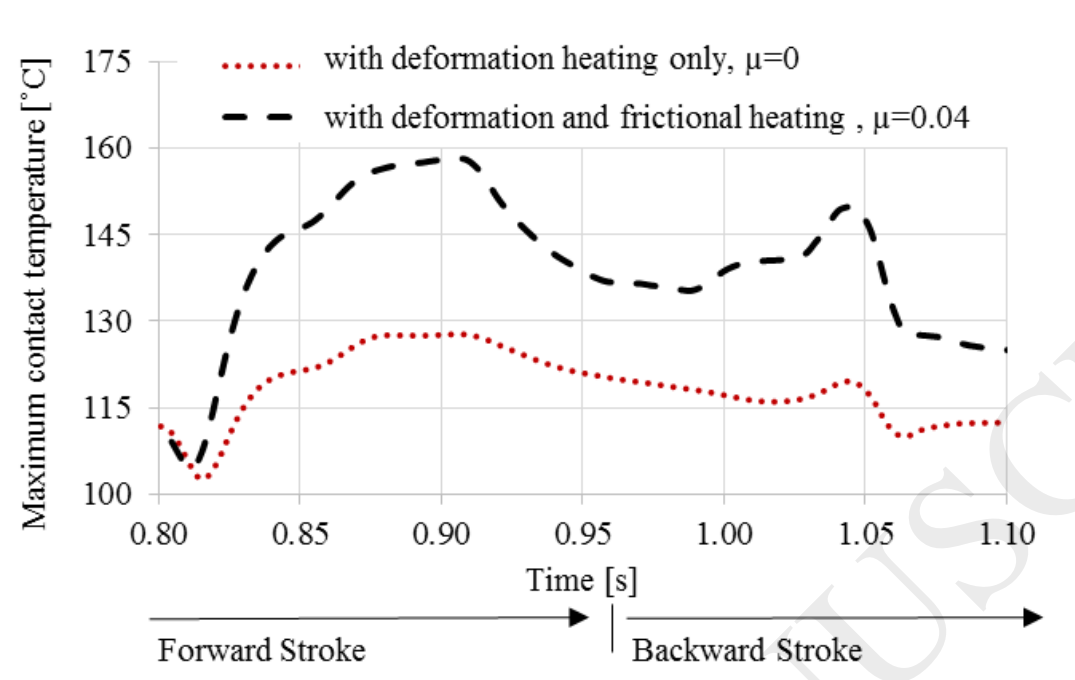

Fig. 10. Instantaneous maximum punch temperature versus time obtained with deformation heating only and with deformation and frictional heating for $\mu=0.04$.

The numerical model was furthermore applied to analyse the temperature development within the tool at various distances from the contact surface. Fig. 11 shows the calculated temperature of nodes B, C and D with the distances $4.375 \mathrm{~mm}, 1.3$ and $0.4 \mathrm{~mm}$ to the contact surface, respectively. Node $\mathrm{E}$ is located on the surface of the punch. The temperature response of the contact node, $\mathrm{E}$, is the fastest node as a consequence of the direct contact with the workpiece undergoing plastic deformation. As soon as the contact ceases, the temperature in node E decreases. As regards node D located $0.4 \mathrm{~mm}$ below the punch surface, the peak temperatures for both forward and backward strokes appear slightly later than observed in contact node E. Moving further away from node E to node C, the fluctuations are almost vanished and replaced by a slight, monotonic increase in temperature and in node B, representing the location of the thermocouple, the temperature is almost constant. Overall, it can be stated that the larger the distance from the contact zone is, the further the delay in temperature increase/decrease response is. Furthermore, while the temperature response and corresponding delay are significant close to the contact zone, the temperature remains almost constant around the inner region of the punch including the region around the thermocouple B. 


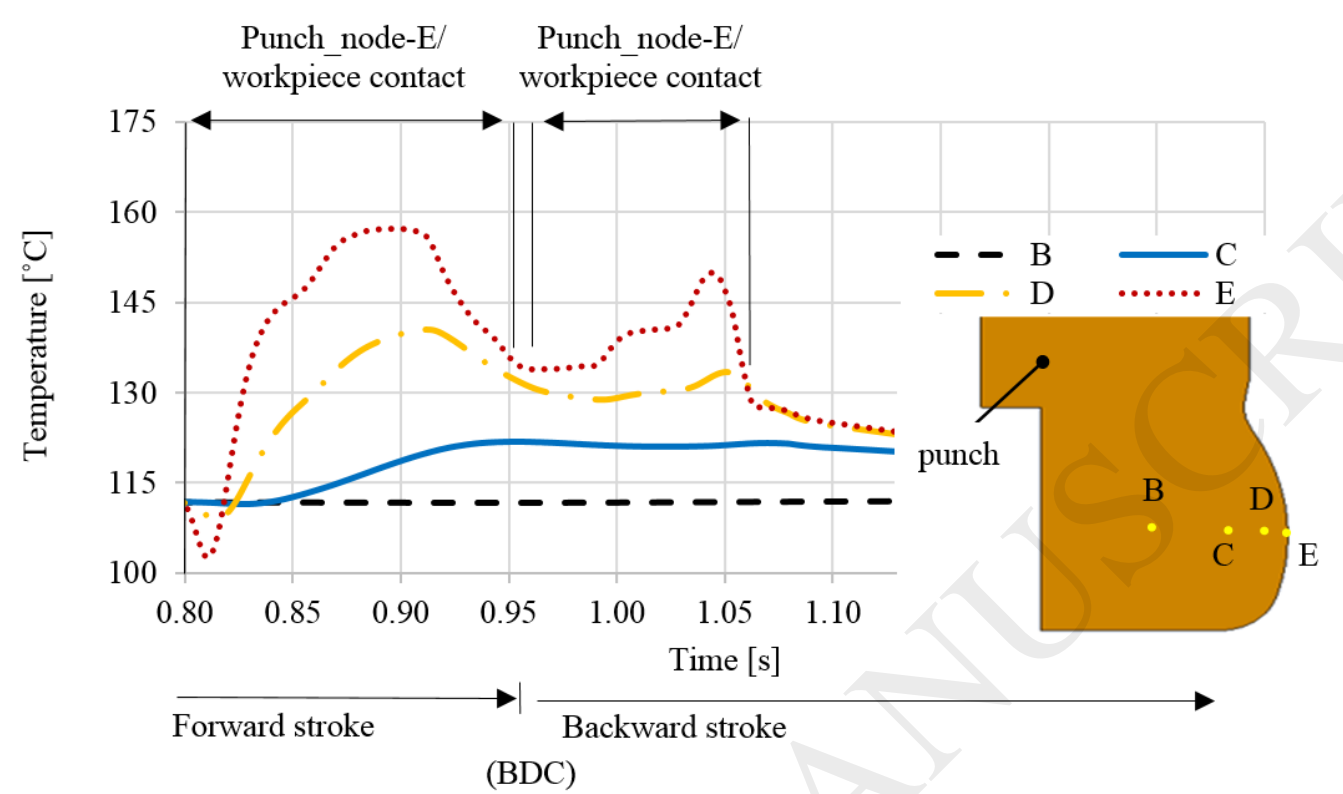

Fig. 11. Numerical temperature evolution of nodes B, C, D and E.

\subsection{Sensitivity Analysis}

In the previous section, the calculated maximum contact temperature was $158^{\circ} \mathrm{C}$ during the forward stroke and $150^{\circ} \mathrm{C}$ during the backward stroke. This section investigates the influence of the predicted tool temperature distribution in steady-state conditions, the selected friction coefficient range and the heat transfer coefficient on the calculated contact temperature.

\subsubsection{Influence of predicted steady-state tool temperature distribution}

The calculated steady-state temperature distribution in the punch was given in Section 3.1. As indicated before, a constant temperature of $40^{\circ} \mathrm{C}$ was assigned to the nodes along the punch base. The referred nodes are marked in yellow within the rectangular box in Fig 12a. The steady-state temperature distribution of the punch was re-calculated by assigning two new base temperatures of the punch, $28.2^{\circ} \mathrm{C}$ and $50^{\circ} \mathrm{C}$. These values were selected as extrema, since the environmental temperature in production was $28.2^{\circ} \mathrm{C}$ and the maximum temperature tip of the punch nose was measured as $50^{\circ} \mathrm{C}$. After obtaining the steady-state temperature distribution of the punch adopting the two new 
boundary temperatures, $28.2^{\circ} \mathrm{C}$ and $50^{\circ} \mathrm{C}$, the thermo-mechanical calculation was performed again with the corresponding, new initial punch temperature distributions.

Fig. 12b shows the maximum interface temperature along the punch nose with respect to time after ironing starts until the end of contact comparing the two new boundary conditions with the earlier one of $40^{\circ} \mathrm{C}$. The results indicate that the temperature of the punch base does not have any significant effect on the maximum punch temperature.

a)

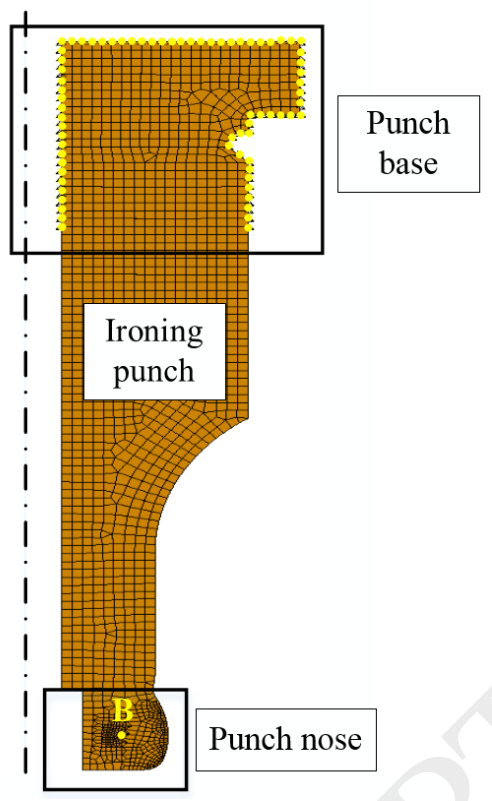

b)

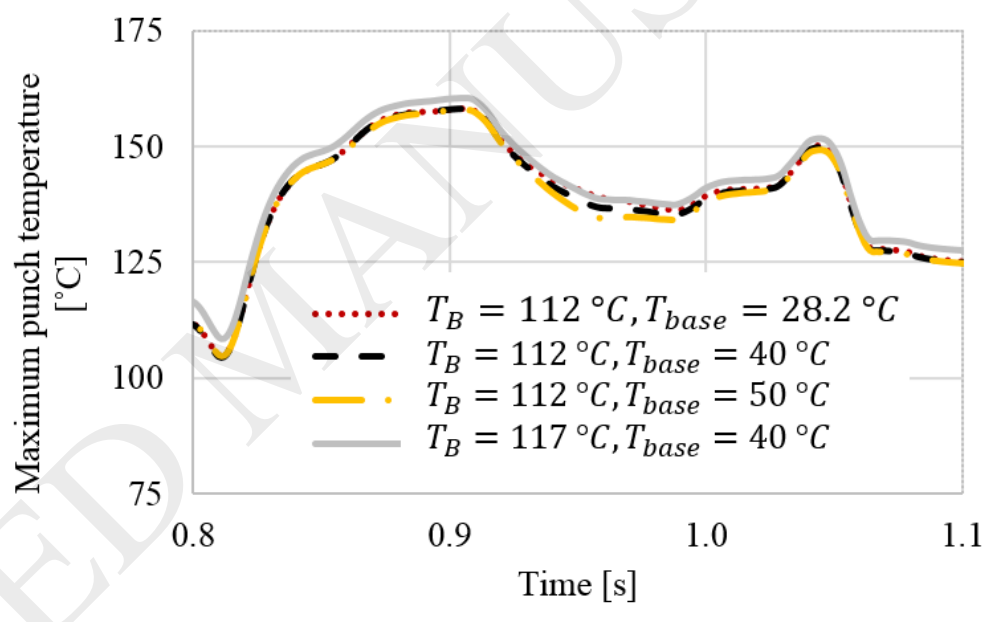

Fig. 12. a) 2D-axisymmetric finite element model of the ironing punch with its regions and representation of prescribed boundary temperatures indicated in yellow, b) Instantaneous maximum punch temperature versus time obtained with different predicted steady-state punch temperature boundary conditions.

To ensure the repeatability of the experimental results, the temperature in the production was measured again. The steady-state temperature $\mathrm{T}_{\mathrm{B}}$ was $117^{\circ} \mathrm{C}$. The steady-state temperature distribution in the punch was re-calculated by assigning a temperature of $117^{\circ} \mathrm{C}$ in node $\mathrm{B}$, which is indicated with a yellow dot in the punch nose region in Fig. 12a. A re-calculated temperature distribution was used as input to the thermo-mechanical model. All other parameters were the same. Fig 12b shows that an increase of $\mathrm{T}_{\mathrm{B}}$ has a larger effect on the maximum contact temperature than an 
increase of the temperature in the punch base. The peak contact temperature increased around $2^{\circ} \mathrm{C}$ when $\mathrm{T}_{\mathrm{B}}$ was raised from $112{ }^{\circ} \mathrm{C}$ to $117^{\circ} \mathrm{C}$ in the steady-state analysis.

\subsubsection{Influence of the friction coefficient}

In the previous calculations, a coefficient of friction $\mu=0.04$ was assumed. To investigate the influence of the friction coefficient, FEM simulations were carried out with two alternative values; $\mu=0.03$ and $\mu=0.05$.

Each case was calculated in two consecutive strokes. Fig. 13a represents the numerically computed temperature versus time of node B and the corresponding experimental temperature curve. The numerical simulations show that a friction coefficient of $\mu=0.05$ overestimates the temperature increase, whereas; $\mu=0.03$ gives lower temperature increase than experimentally measured. Although the current study suggests that the friction coefficient is $\mu=0.04$, one may claim that depending on the model assumptions and other process parameters, the friction coefficient may change slightly. However, in this study the main interest is to determine the contact temperature. Fig. 13b shows the maximum temperature of the punch surface to be $158 \pm 8^{\circ} \mathrm{C}$ in the forward stroke is and $150 \pm 6^{\circ} \mathrm{C}$ in the backward stroke in the range $0.03 \leq \mu \leq 0.05$.

a)

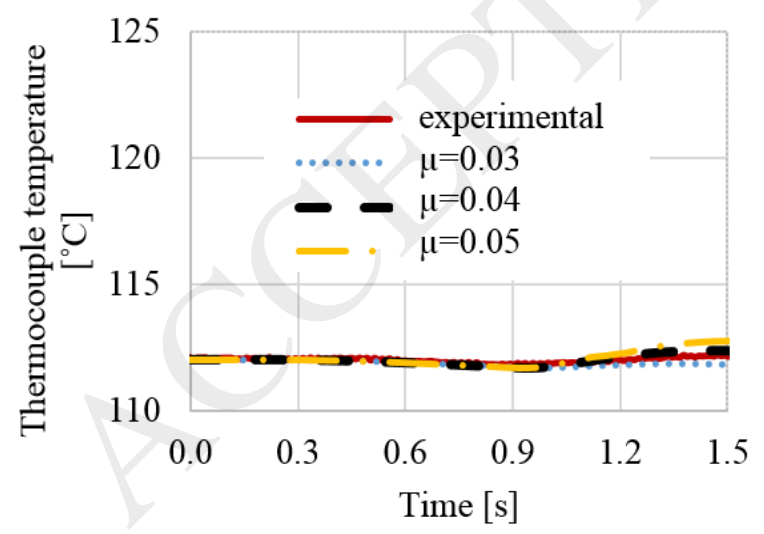

b)

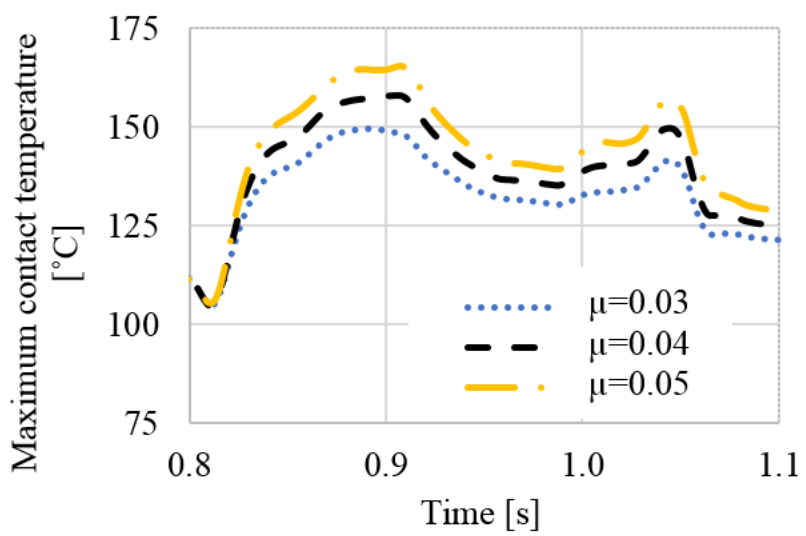

Fig. 13. a) Numerical and experimental temperature evolution at thermocouple B position and b) maximum contact temperature evolution with various friction coefficients $\mu=0.03,0.04$ and 0.05 . 


\subsubsection{Influence of heat transfer coefficient}

To investigate the influence of the heat transfer coefficient (HTC) calculations were performed with three different values: $\mathrm{h}=50,100$ and $150 \mathrm{~kW} /\left(\mathrm{m}^{2} \cdot \mathrm{K}\right)$. The selection of $\mathrm{HTC}$ was based on the values proposed by Olsson et al. (2004), who investigated a single-stroke strip reduction test at various reductions. The assumption of a constant heat transfer coefficient along the tool-workpiece interface is considered acceptable since the heat transfer coefficient is insensitive to the pressure in forging above a threshold pressure as shown by Burte et al. (1990) for a deformation process with a pressure range similar to that of the present ironing. The friction coefficient was $\mu=0.04$, and as Burte et al. (1990) has found, the effect of the friction coefficient on the heat transfer coefficient calibration curves is small. The heat transfer and the friction may therefore be decoupled in the sensitivity analysis.

a)

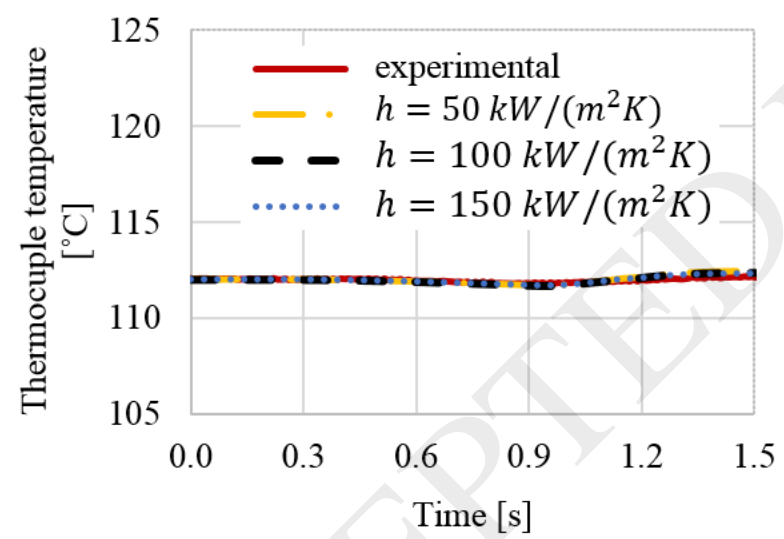

b)

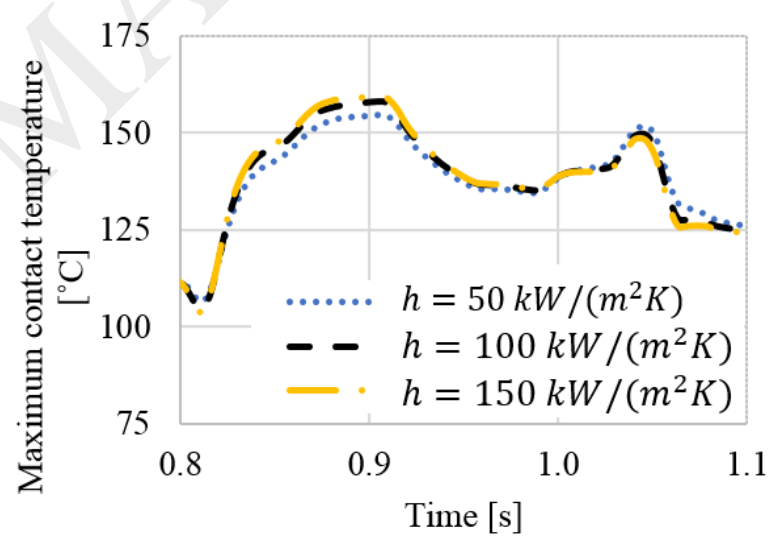

Fig. 14. a) Numerical and experimental temperature evolution at thermocouple B position and b) maximum contact temperature evolution with various heat transfer coefficients $\mathrm{h}=50,100$ and $150 \mathrm{kW/} /\left(\mathrm{m}^{2} \mathrm{~K}\right)$.

In Fig. 14a, the numerically computed temperature curves versus time of node B and the experimental temperature curve are given. The overall temperature distribution inside the punch at the thermocouple position was not sensitive to the changes in heat transfer coefficient. Fig. 14b shows the instantaneous maximum punch temperature. The results indicate that the instantaneous contact temperature tends to be slightly higher for higher heat transfer coefficients. The peak temperature along the punch-workpiece interface is $158 \pm 1^{\circ} \mathrm{C}$ during the forward stroke and $150 \pm 1^{\circ} \mathrm{C}$ during the 
backward stroke. In general, the heat transfer coefficient affects the peak temperature only slightly. Since the transient thermo-mechanical analysis starts with a previously calculated temperature distribution corresponding to the steadystate, the heat transfer coefficient has less effect on temperature increase at higher speeds.

\section{Summary and Conclusions}

When testing the performance of new tribo-systems for sheet forming operations with simulative laboratory tests, it is vital to ensure similar values of the main tribo-parameters, such as normal pressure, sliding length, sliding velocity and tool-workpiece interface temperature.

The present paper shows the determination of the interface temperature for an industrial ironing operation, where severe process parameters lead to lubricant film breakdown and galling. The analysis was performed by means of a combined numerical-experimental approach that uses the experimental measurements of the tool temperature in a few points at thermal steady-state to define appropriate boundary conditions in the subsequent thermo-mechanical analysis.

The analysis of the heat generation within the punch and the strip for various friction conditions showed that:

- The temperature gradients in the tool and workpiece are significantly larger when including friction in the calculations. Higher friction results in higher interface temperature.

Furthermore, a sensitivity analysis was performed to analyse the effect of selected parameters such as steady-state tool temperature distribution, friction coefficient and heat transfer coefficient. It was found that:

- Experimentally measured temperatures used for determining the steady-state tool temperature distribution must be as close as possible to the contact surface. The closer the measured temperature is to the contact interface, the larger its effect on the predicted interface temperature changes is.

- The friction coefficient has a large influence on the interface temperature, whereas the heat transfer coefficient has no practical effect when the process is already in steady-state.

- The peak temperature in the tool-workpiece interface is approximately $158^{\circ} \mathrm{C}$ in the forward stroke and $150^{\circ} \mathrm{C}$ in the backward stroke. 
Future work will include the design of a laboratory test to emulate the found contact temperatures for both forward and backward stroke and testing of several tribo-systems.

\section{Acknowledgements}

The work is supported by the Danish Council for Independent Research [grant no. DFF - 4005-00130]. 


\section{References}

Altan, T. \& Tekkaya, A. E., 2012. Sheet Metal Forming - Fundamentals, first ed. ASM International, Materials Park, Ohio, pp. 117-121.

Bay, N., Eriksen, M., Tan, X., Wibom, O., 2011. A friction model in cold forging of aluminium, steel and stainless steel provided with conversion coating and solid film lubricant. CIRP Annals, Manufacturing Technology, 60/1, pp 303-306.

Burte, P. R., Im, Y.-T., Altan, T., Semiatin, S. L., 1990. Measurment and Analysis of Heat Transfer and Friction During Hot forging. J. Eng. Ind. 112, pp. 332-339.

Ceron, E., Martins, P. A. F., Bay, N., 2014. Thermal analysis of bending under tension test. Procedia Eng. 81, pp. $1805-1810$.

Doege, E., Meyer-Nolkemper, H., Saeed, I., 1986. Fließkurvenatlas metallischer Werkstoffe - mit Fließkurven für 73 Werkstoffe und einer grundlegenden Einführung, Carl Hanser Verlag, München, pp. 113. (In German).

Fallahiarezoodar, A., Peker, R., Altan, T., 2016. Temperature Increase in Forming of Advanced High Strength Steels Effect of Ram Speed Using a Servo Drive Press. J. Manuf. Sci. Eng. 138, pp. 1-7.

Farren, W. S., Taylor, G. I., 1925. The Heat Developed During Plastic Extension of Metals. In Proceedings of the Royal Society of London Series A-containing Papers of a Mathematical and Physical Character, pp. 422451.

Friis, K.L., Nielsen, P.S., Bay, N., 2008. Testing and modelling of industrial tribo-systems for sheet metal forming. In: D.Y. Yang, Y.H. Kim, C.H. Park (Edtrs.): Adv. Technol. of Plasticity 2008, Proceed. 9th Int. Conf. on Technology of Plasticity, Gyeongju, Korea, pp. 209-210.

Henningsen, P., Wanheim, T., Hattel, J., 1998. Measurement of the temperature and determination of heat transfer coefficient in bacward can extrusion. In Proc. 1st ESAFORM Conf. on Material Forming, CEMEF. ESAFORM. 
Jimbo, Y., Hiroshige, T., Azushima, A., 1998. Measurement of Critical Interfacial Temperature by means of the Thermoelectric Method in Cold Sheet Rolling. Journal of Iron and Steel Institute of Japan 84(6), pp. 423-428 (in Japanese).

Nielsen, P. S., Friis, K. S., Bay, N., 2011. Testing and modelling of new tribo-systems for industrial sheet forming of stainless steels. Proc. Inst. Mech. Eng. Part J J. Eng. Tribol. 225, pp. 1036-1047.

Olsson, D. D., Bay, N., Andreasen, J. L., 2004. Prediction of limits of lubrication in strip reduction testing. CIRP Ann. - Manuf. Technol. 53, pp. 231-234.

Outokumpu, 2013. Handbook of Stainless Steel.

http://www.outokumpu.com/sitecollectiondocuments/outokumpu-stainless-steel-handbook.pdf

Pereira, M. P., Rolfe, B. F., 2014. Temperature conditions during 'cold' sheet metal stamping. J. Mater. Process.

Technol. 214, pp. 1749-1758.

Schey, J. A. Schey, 1970. Metal Deformation Processes: Friction and Lubrication. Marcel Dekker Inc.

Shapiro, A. B., Livermore Software Technology Corporation, 2003. Heat Transfer in LS-DYNA. In Proceedings of the 4th European LS-SYNA Users Conference, pp. 1-8.

Üstünyagiz, E., Nielsen, C.V., Tiedje, N.S., Bay, N., 2018. Combined numerical and experimental determination of the convective heat transfer coefficient between an AlCrN-coated Vanadis 4E tool and Rhenus oil. Measurement 127, pp. 565-570.

Vanadis® 4 Extra Superclean, 2017. Data Sheet, Edition 11.

http://www.bucorp.com/media/vanadis4_extra_data_sheet.pdf

van der Heide, E. Schipper, D. J., 2003. Galling initiation due to frictional heating. Wear, 254(11), pp. 1127-1133.

Wibom, O., Nielsen, J.Aa., Bay, N., 1994. Influence of Tool Temperature on Friction and Lubrication in Cold Forging of Steel. WIRE 44, pp. 275-281. 


\section{Figure Captions}

Fig. 1. a) Tool set-up for ironing, open tool, b) set-up during ironing, c) ram speed as a function of ram displacement. The direction of the velocity pattern is clockwise. BDC and TDC indicate the bottom and top dead centers.

Fig. 2. a) Schematic drawing of the ironing punch, b) top view of the ironing punch with main components used in assembly, c) assembled ironing punch and main components seen from below.

Fig. 3. a) 2D-axisymmetric finite element model of the ironing punch and location of the prescribed temperature boundary input nodes A and B. b) Steady-state temperature distribution in the punch.

Fig. 4. Representation of thermo-mechanical coupling (Shapiro, 2003).

Fig. 5. Representation of 2D-axisymmetric, thermo-mechanical finite element model.

Fig. 6. Flow stress curve for EN 1.4301 obtained from plain strain compression tests.

Fig. 7. Ram speed and displacement as a function of time with identification of the ironing process window.

Fig. 8. a) Experimental temperature evolution of thermocouple B in production test and b) numerical and experimental temperature evolution of thermocouple B for three consecutive temperature cycles after stroke number 150 .

Fig. 9. a) Ram displacement versus time during the ironing process with the details of forward and backward stroke time intervals and indication of time where the temperature distributions are shown. Temperature distribution with respect to $\mathrm{r}$-coordinate for $\mathrm{b}$ ) forward stroke at $\mathrm{t}=0.88 \mathrm{~s}$, and c) backward stroke at $\mathrm{t}=1.04 \mathrm{~s}$.

Fig. 10. Instantaneous maximum punch temperature versus time obtained with deformation heating only and with deformation and frictional heating for $\mu=0.04$.

Fig. 11. Numerical temperature evolution of nodes B, C, D and E. 
Fig. 12. a) 2D-axisymmetric finite element model of the ironing punch with its regions and representation of prescribed boundary temperatures indicated in yellow, b) Instantaneous maximum punch temperature versus time obtained with different predicted steady-state punch temperature boundary conditions.

Fig. 13. a) Numerical and experimental temperature evolution at thermocouple B position and b) maximum contact temperature evolution with various friction coefficients $\mu=0.03,0.04$ and 0.05 .

Fig. 14. a) Numerical and experimental temperature evolution at thermocouple B position and b) maximum contact temperature evolution with various heat transfer coefficients $\mathrm{h}=50,100$ and $150 \mathrm{~kW} /\left(\mathrm{m}^{2} \mathrm{~K}\right)$.

\section{Table Captions}

Table 1. Material parameters used in numerical simulations. 